\title{
BMJ Open Impact of the COVID-19 pandemic on children and adolescents with autism spectrum disorder and their families: a mixed-methods study protocol
} \begin{tabular}{l}
\hline Linda Dekker (D , $, 1,2$ Linde Hooijman, ${ }^{1,2}$ Anneke Louwerse, ${ }^{2,3}$ Kirsten Visser, \\
Dennis Bastiaansen, ${ }^{2,5}$ Leontine Ten Hoopen, ${ }^{2,3}$ Pieter De Nijs, ${ }^{2,3}$ Gwen Dieleman, ${ }^{2,3}$ \\
Wietske Ester, ${ }^{2,4,6,7}$ Susan Van Rijen, ${ }^{1,2}$ Femke Truijens,,${ }^{1,2}$ Ruth Van der Hallen (i)
\end{tabular}

To cite: Dekker L, Hooijman L, Louwerse A, et al. Impact of the COVID-19 pandemic on children and adolescents with autism spectrum disorder and their families: a mixed-methods study protocol. BMJ Open 2022;12:e049336. doi:10.1136/ bmjopen-2021-049336

- Prepublication history and additional supplemental material for this paper are available online. To view these files, please visit the journal online (http://dx.doi.org/10.1136/ bmjopen-2021-049336).

Received 01 February 2021 Accepted 03 December 2021

Check for updates

(c) Author(s) (or their employer(s)) 2022. Re-use permitted under CC BY-NC. No commercial re-use. See rights and permissions. Published by BMJ.

For numbered affiliations see end of article.

Correspondence to

Dr Linda Dekker;

I.p.dekker@essb.eur.nl

\section{ABSTRACT \\ Background}

The COVID-19 pandemic is a challenge for everyone, particularly for children and adolescents with autism spectrum disorder (ASD). ASD is a developmental disorder characterised by limitations in social communication, repetitive behavioural patterns, and limited interests, and activities. It is expected that many families with children with ASD will experience more problems due to the COVID-19 pandemic and the related public health restrictions. At the same time, some may experience improved functioning, due to fewer expectations and social demands.

\section{Methods/design}

In a mixed-method study to identify the impact of the COVID-19 pandemic, parents of children with ASD (ages 4-21) who were in care pre-COVID-19 at one of three large mental healthcare institutions in the region of Rotterdam participated (68 for T0, 57 for T1). The aims are (1) to investigate the impact of the COVID-19 pandemic on overall functioning and autistic symptoms of the child/adolescent with ASD, as well as parental and family functioning (QUANT-QUAL), in both the short term and longer term, and (2) to investigate risk and protective factors (in light of resilience) (QUANT-qual) and (3) to investigate care and informational needs (QUAL-quant). Pre-COVID-19 baseline data will be retrieved from clinical records. Participants will fill out two surveys (one during a COVID-19 peak-JanuaryMay 2021 - and one thereafter). Survey participants were invited to participate in interviews $(n=27)$. Surveys include measures thar were included pre-COVID-19 (ie, overall functioning and autism symptoms) as well as specific measures to identify family functioning and COVID-19 impact. The semistructured interviews focus on child, parent and family functioning and care—and informational needs.

\section{Ethics and dissemination}

The Medical Ethics Committee of the Erasmus MC has approved the study. Findings will be available to families of children with ASD, their care providers, the funders, autism societies, the government and other researchers.

\section{INTRODUCTION}

While challenging to each and every one of us, the COVID-19 pandemic may be
Strengths and limitations of this study

- As pre-COVID-19 clinical data are available, a natural experiment occurs in which direct comparisons in functioning can be made from pre-COVID-19 to during COVID-19 functioning of children/adolescents with autism spectrum disorder.

- The mixed-method design allows a comparison between quantitative and qualitative data for clarification, nuancing and validation (mixed-methods research), as well as an exploration of unknown or unanticipated experiences and needs (qualitative research)

- The primary limitation is the dependence on preCOVID-19 data from three different clinical institutions, which may mean that not all participants have the same baseline measurement(s).

- A potential limitation is the risk that less participants may be willing to partake than expected (both at T1 and T2).

particularly challenging for children and adolescents with autism spectrum disorder (ASD) and their families. ${ }^{1-6}$ ASD is an earlyonset neurodevelopmental condition characterised by a co-occurrence of impairments in social reciprocity and social communication, and rigid, repetitive patterns of behaviour, interest or activities. ${ }^{7}$ Worldwide prevalence is estimated at $1 \%$ of the population, ${ }^{8}$ and many present with co-occurring conditions such as anxiety and depression. ${ }^{10}$ While ASD is best-known for its profound impact on the socialemotional domain, its impact on the non-social domain, which includes externalising behaviour, atypical responses to sensory input, difficulty processing non-verbal information and anticipating the behaviour of others, should not be overlooked. ${ }^{1112}$ The key diagnostic criteria, related to socialemotional challenges and rigid, repetitive patterns of behaviour, interest and activities, in addition 
to information processing difficulties and comorbid disorders (eg, anxiety), could lead to both an increase as well as a decrease of problems given pandemic related measures that are taken such as nation-wide lockdowns, social distancing, less face-to-face and more online social contact, and the use of face masks.

Indeed, recent studies considering the impact of the COVID-19 pandemic and its associated public health measures on individuals with ASD and their close ones show mixed results. Several authors suggest that individuals with ASD may pose a particularly vulnerable population $^{13-16}$, yet only a handful of empirical studies have investigated the impact of the COVID-19 pandemic on individuals with ASD. For instance, a recent study by Nonweiler et at showed that, during a COVID-19 related lockdown in the UK, children and young people with neurodevelopmental disorders ( $\mathrm{n}=106$ with ASD) compared with neurotypicals $(n=82)$ experienced more emotional and behavioural problems and presented with less prosocial behaviour. Moreover, two Italian studies ${ }^{17} 18$ found increased problematic behaviour and intensity of autistic symptoms in children with ASD as measured during a COVID-19-related lockdown in Italy spring 2020. In addition, a large cohort study in the USA ${ }^{19}$ found that the pandemic led to significant disruptions in therapies, worsened ASD symptoms and family distress. In a broader sense, the Co-Space study ${ }^{20}$ has found that children with special educational needs and/or neurodevelopmental difficulties (among whom children with ASD) have elevated levels of behavioural, emotional and attentional difficulties, which have not subsided post-lockdown in this group contrary to neurotypicals. Along that line, a study by Mutluer $e t a l^{21}$ revealed that special needs education was either partially or completely suspended as during the COVID-19 pandemic, and noted more behavioural problems. Other authors have also suggested that school disruption may potentially result in frustration..$^{22}$ The increased complexity of social interaction with different social cues in online communication, a decrease in exposure to social situations, routines that have been broken, disrupted mental healthcare services, and information and public health restrictions which are constantly changing may all contribute to increases in behavioural and emotional problems, such as more restricted, repetitive behaviours, sleep problems, anxiety, depression and aggression. ${ }^{21} 2324$

Along with individuals with ASD, relatives of individuals with ASD, like their parents or siblings, may also find themselves particularly challenged during the pandemic. Most informal support and professional mental healthcare guidance were significantly reduced due to the pandemic measures, known to be important protective factors for parents and families under normal circumstances. ${ }^{25}$ Informal support, particularly one's satisfaction with informal support, is known to predict family resilience, ${ }^{26}$ that is, a lack thereof is likely to decrease such family resilience. Actually, during a school-closure period in the UK, it was found that a large portion of families with children with special educational needs ( $>80 \%$ ASD) experienced negative effects on their mental health, with more anxiety, stress and lower mood. ${ }^{27}$ Moreover, a recent COVID-19 study in Turkey found that mothers of children with ASD had more health anxiety, less dispositional hope and less psychological well-being compared with mothers with neurotypical children. ${ }^{28}$ Similarly, parents of children with ASD in Saudi Arabia were negatively impacted (ie, more stress and less emotional well-being) by the COVID-19 pandemic. ${ }^{29}$ It seems that particularly parents of school-aged children had an increase in overall distress, which may increase their risk of crises. ${ }^{19}$ Relatives of individuals with ASD have to both assist their affected family members, and face other potential challenges such as work demands or financial worries. ${ }^{30}$ Role confusion, that is, having to navigate the role of parent, advocate, educator, spouse, and so on, is most likely increased as well. ${ }^{31}$ Overall, the COVID-19 pandemic and corresponding measures seem to affect relatives of individuals with ASD by an increase in stress and decrease in overall well-being family resilience. ${ }^{1171926}$

Interestingly, while the beforementioned ASD characteristics may thus leave individuals with ASD as well as their relatives at increased risk, some of these characteristics may also serve as a protective factor at the same time. ${ }^{32}$ As the COVID-19 pandemic includes mandatory distancing, less-to-no exposure to group activities, and less social interaction, some individuals with ASD may benefit from the measures related to the pandemic. ${ }^{33}$ For example, they might feel less pressured by society to participate in everyday (social) life, typical sensory overstimulation might be reduced, or they may be able to engage more in the repetitive behaviours which soothe them and decrease anxiety. ${ }^{23}$ Moreover, individuals with ASD may, all of a sudden, feel less different from neurotypicals, as during the pandemic most people spent their time alone at home with little-to-no social activities. As such, individuals with ASD may experience less rejection or bullying, feel less stigmatised or outside the norm, reducing so-called minority stress ${ }^{27} 34$ and potentially improving overall functioning. ${ }^{35}$ Lastly, individuals with ASD may benefit from more online compared with offline social interaction with friends as an online environment may elicit less anxiety, allowing friendships to blossom. ${ }^{36}$ During the COVID-19 pandemic, parents to individuals with ASD may also have gained new, positive experiences in dealing with their child (eg, maintaining a schedule for their children, learning new skills to their child and setting boundaries), resulting in potential positive longterm effects. ${ }^{33} 37$

Taken together, previous research suggests that, while a pandemic may prove challenging to each and every individual, individuals with ASD and their relatives may prove particularly vulnerable. ${ }^{3} 151618$ Individuals with ASD and their relatives present with characteristics that may limit coping and resilience in light of the COVID-19 pandemic as well as the continuously changing public health measures, putting them at risk for negative 
outcomes, such as stress, anxiety, depression, loneliness, a decline in general functioning, increase autistic symptoms, and confusion regarding the COVID-19 measures. 151618192123243839 Moreover, previous research has shown that major-life events, trauma and stress can have a long-lasting impact on mental health in individuals with ASD ${ }^{40}$ which leads to the expectation that the COVID-19 pandemic too will have long-term consequences for individuals with ASD and their families. In addition, relatives of individuals with ASD may be subject to significant stress as well, due to extra role confusion and the extra burdens put on them. ${ }^{1728} 29$

However, all but one of the beforementioned research studies lack a direct pre-COVID-19 baseline measure. Some studies asked participants if they experienced an increase in symptoms or difficulties as a result of the pandemic or its consequent measures ${ }^{17}$ or compared a subgroup to a larger cohort $^{19}$, or compared different groups (eg, neurotypicals with a group with neurodevelopmental disorders ${ }^{4}$ ), but no direct baseline measure was available to compare during COVID-19 with preCOVID-19. In addition, the results depend on either quantitative $^{18}$ or qualitative data. ${ }^{30}$ Given the limitations of these studies, it gives a limited understanding of the impact of the current pandemic as specific to individuals with ASD and their families. To date, no research has been conducted into the impact of a large-scale event in this target group using a baseline measure as well as a mixed-method design.

The aim of the current study is threefold; (1) to investigate the impact of the COVID-19 pandemic on overall functioning and autistic symptoms of the child/adolescent with ASD, as well as parental and family functioning (QUANT-QUAL), in both the short term and longer term, and (2) to investigate risk and protective factors (in light of resilience) (QUANT-qual) and (3) to understand the care and information needs during such an event
(QUAL-quant). The study will take place in collaboration with three mental healthcare institutions providing specialised care to families of children with ASD in South Holland.

This unique and robust study design can inform and improve care in both the short- and long-term so that any negative impact of the pandemic for this group is minimised. Moreover, the information resulting from this project will allow for a better specification of guidelines for mental healthcare both during and after the COVID-19 pandemic, as well as other future impactful events, to better support individuals with ASD and their families and to minimise any long-term negative impact.

\section{METHODS \\ Study design}

This study is a mixed-method multicentre cohort study involving parents/guardians/caregivers (referred to as 'parents') of a child or adolescent with ASD (see figure 1). The study will be conducted in the larger Rotterdam region of the Netherlands. Clinical data pre-COVID-19 (1 March 2019, until 1 March 2020) of the participants will serve as baseline data (T0). Participants were invited to join the study during the second lockdown in the Netherlands between 4 January 2021, and 31 May 2021 (T1). Potential participants were invited to partake in the study through their clinical institution primarily via email with an informational brochure including a consent form. Consent could be given either on paper or online. If no response was received for 1 week the research assistant did a follow-up via telephone. The quick turnaround was due to the time-sensitivity of COVID-19 research. Participants who did not want to partake were asked to answer a few questions on their motivation, to allow for some attrition analyses later. Active consent was acquired to share any unforeseen but relevant findings to medical health

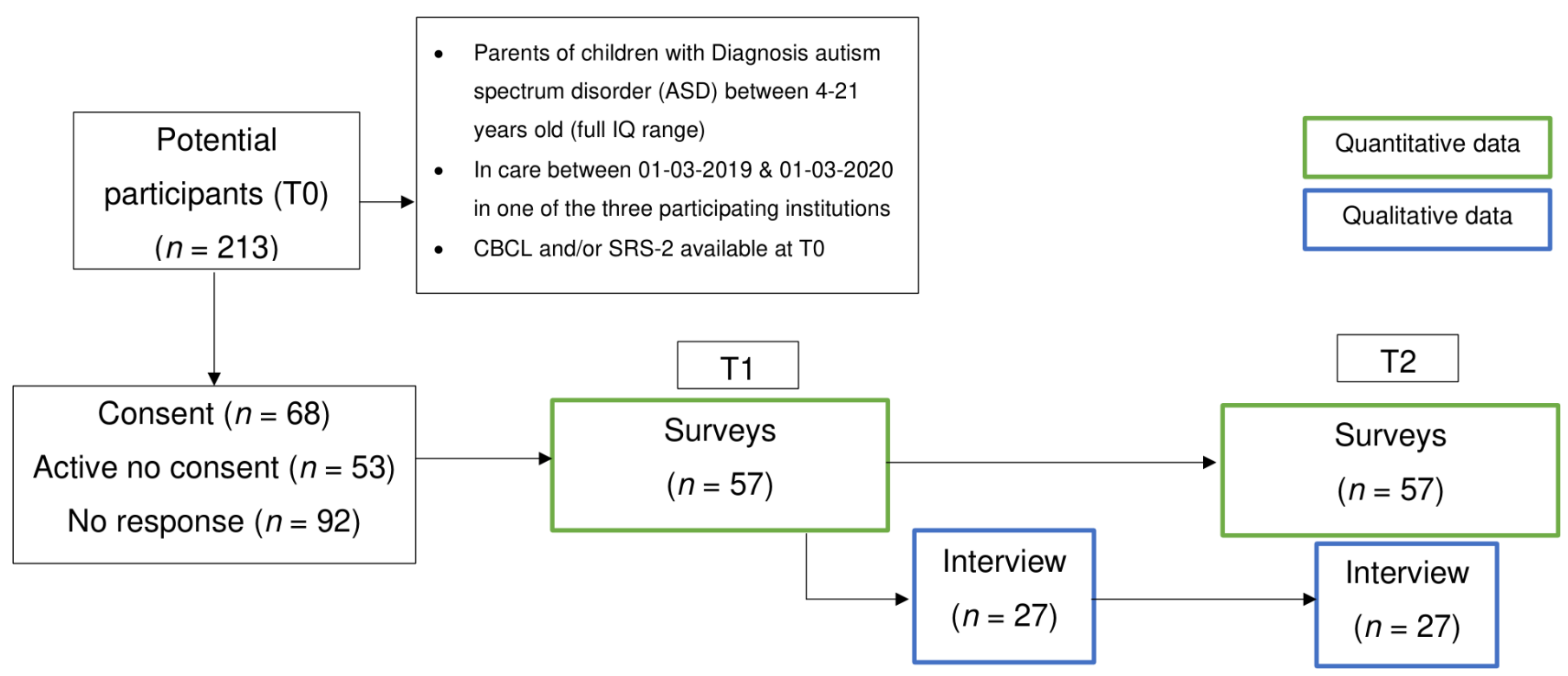

Figure 1 Study design. CBCL, Child Behaviour Checklist; SRS-2, Social Responsiveness Scale. 
professionals if needed. Participants were informed they could stop with the study at any point, without it impacting their care as usual and without providing a reason. In addition, they were informed that data collected up until the point that they indicated they no longer wanted to participate, will be used.

For the quantitative strand of the study, following informed consent, participants received an invitation link to an online survey. A second survey is tentatively planned for the Fall of 2021 (T2; expected to run from mid-September until 31 December 2021) in a period with fewer COVID-19 infections and less restrictive public health measures.

For the qualitative strand of the study, participants who participated in the survey at $\mathrm{T} 1$ were invited to a semistructured interview regarding family functioning, quality of life, and care, and informational needs. All interviewees at $\mathrm{T} 1$ will be invited again for an interview at T2. The semistructured interview covers spontaneous reporting and prioritising (A), adaptations experienced (B), emotional impact on the child (C) and the parent (D), information and care needs $(\mathrm{E})$, role confusion $(\mathrm{F})$ and experiences with the study and/or need for care poststudy (G) (for more detail, see online supplemental appendix A).

Participants receive financial compensation for their participation ( $\mathrm{T} 1$ survey $€ 10$; T2 survey $€ 25$; T1 interview $€ 25$ and $\mathrm{T} 2$ interview $€ 50$ ). A graded compensation was set up to promote long-term participation and minimise drop-out.

\section{Participants}

All parents with children diagnosed with ASD (4-21 years old) of whom clinical data, that is, the Child Behaviour Checklist (CBCL) and/or Social Responsiveness Scale (SRS-2), is available between March 2019 and March 2020 (pre-COVID-19) at one of the three collaborating mental healthcare institutions, were approached for participation $(\mathrm{n}=213)$. In total 68 parents provided consent for gathering T0 data. At T1, 57 parents of children and adolescents with ASD participated in the survey. Sampling for the interview was open and voluntary (self-selection); in total 27 parents signed up for participation and participated in the interview. In all future publications for which quantitative and/or qualitative data is used, the demographic characteristics of that subsample will be reported. Exclusion criterium for the study is the participant does not provide active consent.

Participants were informed that clinical follow-up, support, or referral by clinically trained team members was available in case of adverse effects of study participation.

\section{Sample size calculation}

The aim is to detect differences with a small to medium effect size $(d=0.4-0.5)$ with $95 \%$ power. When translating such effect size in terms of clinical impact, this would mean $25 \%$ of the surveyed group experiences a significant change. ${ }^{41}$
For the quantitative data, aiming to investigate the impact of the COVID-19 pandemic as well as identify the risk/protective factors, data will be evaluated using t-tests, to identify impact (T0 vs T1/T2), and single- or multiple regression, to identify variables which may explain (a change in) functioning at T1/T2 compared with T0. As such, power calculations using $G^{*}$ Power indicate a sample size of $\mathrm{N}=34-59$ for correlations, and a sample of $\mathrm{N}=45-70$ for regression analyses should result in sufficient power.

For the qualitative data, no a priori power analysis is conducted. At the end of the survey at T1 participants were asked if they wanted to also participate with the interviews. In total 27 parents participated in the interviews. This sample size will allow for both deductive and inductive analyses depending on specific qualitatively or mixed-method oriented research questions, such as the experience of agency and family dynamics, role-confusion/change and parental burden due to the COVID-19 pandemic. For these questions, subsamples will be used in which sample size will be determined based on, for example, the qualitative saturation principle ${ }^{42}$ or a mixed-method design in which we deductively deepen quantitative data. Samples will be selected either based on random sampling, purposive qualitative sampling, or purposive quantitative sampling. For instance, for research question 2 (parental burden) parents who score high on parental load on the Parenting Stress Questionnaire (PSQ; in Dutch: Opvoedingsbelastingvragenlijst (OBVL) ) may be selected. ${ }^{43}$ For the impact of COVID-19 on the families and the multiple roles parents may have to play (caregiver; informer, therapist; teacher; etc) (research question 5) we will use a grounded theory framework to capture the development of experiences within families and identify if parents experience role confusion due to the multiple roles they have play, more during the pandemic than normally. From previous literature it is known that chaos is particularly problematic in families with children with ASD, ${ }^{44}{ }^{45}$ and parents can play a critical role in managing chaotic circumstances for their children with ASD. Given the challenges the pandemic puts on everyone, including additional stress for parents, no predefined hypothesis can be formulated, but based on general theory one may expect this theme to be important. For this question, we do not exclude participants a priori but analyse the full sample until saturation is reached (ie, random sampling until saturation). If, contrary to expectations, saturation is not reached within the current sample, additional funding will be applied for continued sampling. If this is not feasible due to practical limitations, such as the impossibility to return to a time frame with specific COVID-19 measures, the findings will be presented in open science framework for triangulation with other possible study findings.

\section{Measures}

Demographics (T0, T1, T2)

Age, gender, nationality, educational level, language skills, intelligence quotient (FSIQ, and if available 
other indices), medication use, and family composition are obtained from the surveys or from clinical records. Gender will be scored as female, male or other. Nationality will be extracted from the electronic patient files, based on parent nationalities the child's nationality will be determined. This will be divided into seven subgroups: Dutch, Surinamese, Turkish, Moroccan, Antillean, Cape Verdean and other. Parents will be asked what type of education their child receives (eg, primary or secondary, regular or special education) during the survey. Language skills of the child during the baseline measurement will be scored as fluent, telegraphic, no spoken language or not specified, if available from clinical records. If an IQ test was conducted as part of the diagnostic or guidance procedure, this will be noted as well including the relevant outcome(s) of the IQ test. Lastly, the family composition will be obtained (eg, single or partnered parenting, siblings, relation to the child in question).

\section{Overall functioning (T0, $\mathrm{T} 1, \mathrm{~T} 2)$}

To determine overall functioning of the children with ASD, several Achenbach System of Empirically Based Assessment ${ }^{46}$ questionnaires will be used, which are commonly used in the clinical care institutions for youth (up to the age of 21). At baseline, overall functioning could be reported by a parent/guardian by filling out the $\mathrm{CBCL},{ }^{47}$ as part of standard care. Each item is scored on a 3-point Likert scale ranging from 0 , not at all to 2 , clearly to describe the behaviour of the child during the last 6 months. The CBCL consists of an Internalising (subscales: anxious/depressed, somatic complaints and withdrawn/depressed) and an Externalising domain (subscales: Rule-Breaking Behaviour and Aggressive Behaviour). A total problems score can also be determined, this score gives a general view of the extent of both behavioural and emotional problems based on the scores of the two domains and the three remaining syndrome scales: Thought Problems, Social Problems, and Attention Problems. The CBCL 6-18 parent-report has high test-retest reliability, internal consistency and criterion validity. ${ }^{48}$

Overall functioning during the pandemic ( $\mathrm{T} 1$ and T2) will also be assessed, for which the Brief Problem Monitor-Parent form (BPM-P) ${ }^{49}$, a shortened version of the CBCL. The BPM-P will be scored similar to the original CBCL on a 3-point Likert scale ranging from 0 , not at all to 2, clearly. The internal consistency of the BPM was high, and the total score of the CBCL and the BPM-P highly correlate. ${ }^{50}$

If the participant was $\geq 12$ years at baseline, self-reported overall functioning will also be included if available, by means of the Youth Self Report (YSR). ${ }^{51}$ The CBCL and the YSR can be transformed into similar domains and syndrome scales. Good reliability and validity have been confirmed for the Dutch version of the YSR in the Dutch population by Verhulst $e$ t $a l^{48}$
ASD characteristics (T0, T1, T2)

To assess ASD characteristics within the children, the Dutch version of the parent-report SRS-2, ${ }^{52}$ and if applicable the self-report SRS-A, ${ }^{53}$ will be used, which can be part of baseline measurements as well. The SRS-2 will be filled out by the parent, the SRS-A is a self-report measure and will therefore be filled out by the adolescent (if $\geq 16$ years old). The SRS-2 is composed of six subscales: (1) Social Awareness, (2) Social Cognition, (3) Social Communication, (4) Social Motivation, (5) Restricted Interests and (6) Repetitive Behaviour. The SRS-2 parent report demonstrated good sensitivity, reliability and validity ${ }^{54}$ The SRS-A has satisfactory psychometric qualities, ${ }^{53}$ and consists of 64 items, which group into four dimensions: (1) Social awareness, (2) Social communication, (3) Social motivation and (4) Restricted interests and repetitive behaviour. Both on the SRS-2 and SRS-A each item is scored on a 4-point Likert scale (not true, sometimes true, often true, always true).

If other relevant diagnostic materials, for example, the Autism Diagnostic Observations Scale, are administered in addition to the SRS-2, the results of both instruments will be documented.

\section{Quality of life (T1 and T2)}

To assess the quality of life of the child with ASD the Dutch version of the Paediatric Quality of Life Inventory $(\text { PedsQL })^{55}$ will be used. The PedsQL will be completed as part of the survey at $\mathrm{T} 1$ and $\mathrm{T} 2$. It will be filled out by the parent/guardian, and if the child is $\geq 12$ years old, by the child as well. The items are scored on a 5-point Likert scale, ranging from 'never a problem' to 'almost always a problem'. The PedsQL is comprised of four subscales: (1) Physical, (2) Emotional, (3) Social and (4) School functioning, as well as a psychosocial health summary and a total score. Satisfactory reliability and validity are reported for the Dutch translation of the PedsQL. ${ }^{55}$

\section{Parenting burden (T1 and T2)}

To assess the parenting burden during the pandemic the Parental Stress Questionnaire (PSQ) (in Dutch: Opvoedingsbelastingvragenlijst; OBVL) will be used. ${ }^{56}$ The PSQ will be completed by the parent/guardian as part of the survey at $\mathrm{T} 1$ and $\mathrm{T} 2$. The items are scored on a 4-point Likert scale, ranging from 'not true' to 'very true'. The PSQ is composed of five domains: (1) parent-child relationship problems, (2) parenting problems, (3) depressive mood, (4) parental role restriction and (5) physical health problems. The instrument has good reliability and validity. ${ }^{57} 58$

\section{Parental functioning (T1 and T2)}

The subscales anxiety and depression of the Brief Symptom Inventory (BSI) ${ }^{59} 60$ will be administered to gain insight into the functioning of parents at $\mathrm{T} 1$ and $\mathrm{T} 2$. The subscales consist of 6 items each which are scored on a 5-point Likert scale, ranging from 'not at all' to 'very much'. 


\section{Impact of COVID-19 (T1 and T2)}

The impact of COVID-19 is explored using a variety of questions which provide important insights about elements that are expected to be impacted by COVID19; for example, general anxious/depressed feelings, the atmosphere at home, effect on the child's sleeping (eg, nightmares and problems with sleeping), social problems (eg, social isolation and loneliness), nonsuicidal self-injury, suicidal thoughts, rumination, and specific COVID-19 elements like experience of infection, behaviour, stress and anxiety (eg, has child/parent been infected, which preventative measures does the child/ parent take, what is the level of confidence in the governmental approach to the pandemic, how worried is the child/parent about becoming sick, how has COVID-19 impacted the work/income of the parent, and any positive experiences related to the pandemic). Some of the questions concerning the impact of COVID-19 are based, for example, on the CoRonavIruS Health Impact Survey ${ }^{61}$ and national collaborations (eg, Grow-it Study, Generation R), or are commonly used overall functioning instruments such as the CBCL. ${ }^{47}$ These questions have not all been validated (yet).

\section{Informational and care needs (T1 andT2)}

The informational and care needs will be assed using questions regarding informational source for child and parents, as well as questions regarding use of care, adaptations made due to COVID-19 and the experience with care during COVID-19, specifically designed for the current study.

\section{Semistructured interview (T1 and T2)}

Family functioning, parental load and the informational and care needs will be assessed using a newly developed semistructured interview for parents, specifically designed for the current study. The themes that will be discussed during this interview (see online supplemental appendix A) are: spontaneously reported experiences of COVID-19 measures (A), experienced changes in daily life/symptoms/family life (B), emotional impact on the child (C) and the parent $(\mathrm{D})$, information and care needs $(\mathrm{E})$, role confusion (F) and experiences with the study and/or need for care poststudy (G-validation and quality control). Interviewers will be trained by FT to ensure uniformity in the interviews. Interviews will be transcribed verbatim by a professional company. Interviews at T1 were administered over the phone or by videocalling.

\section{Analyses}

As both the quantitative and qualitative strands (help) answer our research questions, they each carry equal weight in the umbrella/overall design yet will be entertained in various ways as appropriate per subquestion and integration of strands is done accordingly. The primary research questions we aim to answer: (1) what is the impact of the COVID-19 pandemic on the children and which risk factors can be identified (QUANT-qual);
(2) what is the impact of COVID-19 on parenting/the parents including risk factors (QUANT-QUAL); (3) does COVID-19 impact children/adolescents with ASD differently from typically developing children/adolescents and are there risk/resilience factors (QUANT); (4) what is the impact of COVID-19 on the families (QUAL-quant) and (5) what are the care and informational needs of the participants (QUAL-QUANT). Depending on the research question, emphasis of the paradigm may differ as well as time order decisions. ${ }^{62}$ Research integrity is monitored and reported in each study, following the guidelines of Levitt $e t a l^{63}$ in line with the specific designs of each study.

For research questions which rely solely on quantitative data (QUANT) common quantitative analysis methods, including t-tests, single and multiple regression, repeatedmeasures analysis of variance's and correlations will be employed. For research questions for which quantitative data are supplemented with qualitative data (QUANTqual) the design is sequential, ${ }^{6465}$ where quantitative data are reported first, and qualitative data is used to support/ deepen/illustrate/clarify the findings (deductive analyses). In this design, the relevant parts of the interview will be used from the entire sample (a priori sampling).

For research questions in which qualitative data only (QUAL) or substantiated with quantitative data (QUALquant), is used, inductive analyses are used until saturation based on grounded theory principles. Here, without predefined hypotheses, either overarching themes/ dynamics are identified based on the qualitative data which for some questions can be substantiated/validated/ compared with quantitative data. For example, the impact of having multiple roles within the family as a parent, as described earlier. Alternatively, quantitative data may be used to identify a relevant subgroup (eg, age-deductive/a priori sampling) after which qualitative data are used to answer the research question. ${ }^{66}$ Qualitative data are, therefore, analysed both deductively and inductively depending on the research question.

\section{Patient and public involvement}

Patients nor public parties were involved in the first design of the study given the urgency of the study. However, clinicians took part in the design of the study. In addition, after funding but prior to ethical approval was acquired several parents/patients (who were not participants) were involved to discuss the study and design as proposed. As soon as data collection has taken place and results have been processed, participants to the study will be informed of the study results via a study newsletter suitable for a non-specialist audience.

\section{Ethics and dissemination}

Medical ethical approval for the study was provided by the Medical Ethics Committee (METC) of the Erasmus MC (MEC-2020-0720). Informed (e-)consent will be obtained prior to participation. 
The EUR data vault of the university will be used for data storage and backup of the data, supported by the Erasmus Data Service Centre. All personal data will be stored with care and the researchers will act within the limits of the General Data Protection Regulation. Study data will be deidentified as much as possible and a master linking log with identifiers will be kept and stored separately from the data, either at the clinical institutions (for quantitative data) or at the Erasmus University Rotterdam vault (for qualitative data). The data will be kept for at least 15 years (in accordance with article 454, paragraph 3 of the Medical Treatment Contracts Act, WGBO).

Due to privacy reasons, there will be restricted access to the data for further research. A request needs to be submitted to the principal investigator (LD) after which the Rotterdam Autism Consortium (founding members are the authors on the current paper) decides if and how the data can be shared, based on ethical and privacy standards which will be defined in a creative commons licence adapted to the requirements within the current study.

Outcomes of the study will be made available as soon as possible to participants and interested parties; to clinicians and other professionals working with families with children with ASD; the government; and Autism Associations and networks in the Netherlands and abroad, by means of for example newsletters, social media, white papers, scientific publications (including preprints), meetings and in the education of students.

\section{DISCUSSION}

The difficulties that often present with $\mathrm{ASD}^{7}$ provides a challenge, as the COVID-19 pandemic has drastically changed the social and educational landscape, with social distancing, less face-to-face social contact, more online interaction, and difficulties interpreting social cues due to face masks. Due to their socialemotional difficulties, this could lead to increased tensions, which in turn may result in difficulties in behavioural regulations as well as emotional stress in children and adolescents with ASD. ${ }^{18} 19$ In addition, many individuals with ASD, children in particular, rely on clear structures and routines in order to function well on a day-to-day basis and minimise externalising behaviour. ${ }^{6768}$ These structures and routines are rarely subject to change under normal conditions. However, the COVID-19 pandemic measures often included lockdowns, with school and day-care closings, limited social gatherings and most of cultural, sporting or religious events cancelled. When schools and healthcare facilities reopen after lockdown, this often involves significant changes as well (eg, different entrance and exit routes, online consultations, mandatory face masks) rather than going back to business as usual, with a second wave of structure and routine disruptions as a result. In addition, there is variation in terms of how strict individuals adhere to the governmentally imposed rules and regulations, ${ }^{69}$ which can also lead to frustration and stress particularly for individuals with
ASD. Lastly, as many individuals with ASD present with comorbid problems, particularly anxiety, depression, and externalising behaviours, in varying rates, ${ }^{9}{ }^{10}$ extra concerns may arise with the COVID-19 pandemic and related measures. Simultaneously, some individuals with ASD may thrive due to decreased typical stressors. ${ }^{32}$ The current study attempts to identify the impact of the public health measures on children with ASD and their families, both positive and negative, the relevant protective and risk factors, and the care and informational needs of this population during these challenging times in a mixedmethod design.

Although the project is still ongoing, there are two noteworthy limitations to our design. First, baseline measurements may vary within limits between the different institutions and participants. As an inclusion criterion is pre-COVID-19 (March 2019-March 2020) availability of the CBCL and/or the SRS-2 (see measures for details) some participants may only have 1 of the measures. However, as this is an inclusion criterion there will be sufficient data to compare pre-COVID-19 functioning to during COVID-19 functioning. Second, possible loss of follow-up data at T2. Given that T0 and T1 have already taken place, there will be at least the possibility of investigating T0 to T1 functioning. In addition, our team has extensive experience with long-term follow-up studies and will exert all efforts to minimise loss of follow-up data, such as the graded compensation. That said, there are also several noteworthy strengths to mention. First, having pre-COVID-19 data which can be compared with during COVID-19 data, we can more objectively determine the impact of the COVID-19 pandemic on the functioning of children with ASD and their families. Second, the mixedmethod design allows for a comprehensive understanding as well as unique insight into the functioning of families with children with ASD during extremely challenging times. Third, a wide range of constructs is being assessed which allows for a comprehensive overview of functioning during the pandemic.

\section{Author affiliations}

${ }^{1}$ Department of Psychology, Education and Child Studies, Erasmus Universiteit Rotterdam, Rotterdam, The Netherlands

${ }^{2}$ Rotterdam Autism Consortium (R.A.C.), Rotterdam, The Netherlands

${ }^{3}$ Department of Child and Adolescent Psychiatry/Psychology, Erasmus MC Sophia Children Hospital, Rotterdam, The Netherlands

${ }^{4}$ SARR Expert Centre for Autism, Youz Child- and Adolescent Psychiatry, Parnassia Group, Rotterdam, The Netherlands

${ }^{5}$ Yulius Autism, Yulius, Mental Health Organisation, Barendrecht, The Netherlands ${ }^{6}$ Child- and Adolescent Psychiatry, Curium-LUMC, Oegstgeest, The Netherlands ${ }^{7}$ Parnassia Bavo Group, Parnassia Bavo Academy, Erasmus MC, The Hague, The Netherlands

Contributors $L D$ and RVdH were responsible for conceptualising the study. LD, LH and RVdH drafted the manuscript. LD, RVdH and FT revised the manuscript after reviewer feedback. AL, KV, DB, LTH, PDN, GD and WE provided access to potential participants and assisted in drafting participants. LD, LH, AL, KV, DB, LTH, PDN, GD, WE, SVR, FT and RVdH all participated and contributed to the design of the study and manuscript development.

Funding This research is supported by a grant from ZonMw, the Netherlands Organisation for Health Research and Development, within the program 'COVID-19 
Focus area 2. Care and prevention, Theme 2: Care and prevention for vulnerable citizens' (project number: 10430022010007).

Competing interests None declared.

Patient consent for publication Not applicable.

Provenance and peer review Not commissioned; externally peer reviewed.

Supplemental material This content has been supplied by the author(s). It has not been vetted by BMJ Publishing Group Limited (BMJ) and may not have been peer-reviewed. Any opinions or recommendations discussed are solely those of the author(s) and are not endorsed by BMJ. BMJ disclaims all liability and responsibility arising from any reliance placed on the content. Where the content includes any translated material, BMJ does not warrant the accuracy and reliability of the translations (including but not limited to local regulations, clinical guidelines, terminology, drug names and drug dosages), and is not responsible for any error and/or omissions arising from translation and adaptation or otherwise.

Open access This is an open access article distributed in accordance with the Creative Commons Attribution Non Commercial (CC BY-NC 4.0) license, which permits others to distribute, remix, adapt, build upon this work non-commercially, and license their derivative works on different terms, provided the original work is properly cited, appropriate credit is given, any changes made indicated, and the use is non-commercial. See: http://creativecommons.org/licenses/by-nc/4.0/.

\section{ORCID iDs}

Linda Dekker http://orcid.org/0000-0001-5720-3296

Ruth Van der Hallen http://orcid.org/0000-0001-6899-4898

\section{REFERENCES}

1 Bosch vandenK. We krijgen geen moment rust. NVA Ned Ver Voor Autisme, 2020. Available: https://www.autisme.nl/nva-autismeweekspecial-2020/ [Accessed 22 Dec 2020].

2 Bouma B. Lockdown. NVA Ned Ver Voor Autisme, 2020. Available: https://www.autisme.nl/nva-autismeweek-special-2020/ [Accessed 22 Dec 2020].

3 Cassidy SA, Nicolaidis C, Davies B, et al. An expert discussion on autism in the COVID-19 pandemic. Autism in Adulthood 2020;2:106-17.

4 Nonweiler J, Rattray F, Baulcomb J, et al. Prevalence and associated factors of emotional and behavioural difficulties during COVID-19 pandemic in children with neurodevelopmental disorders. Children 2020;7:128.

5 Wevers J. NVA - AVG-arts: "Wij zien vooral héél veel angst ontstaan." NVA Ned. Ver. Voor Autisme, 2020. Available: https://www.autisme. $\mathrm{nl} / 2020 / 04 / 10 /$ wij-zien-vooral-heel-veel-angst-ontstaan/ [Accessed 22 Dec 2020].

6 Pachner O, Aranyi G. Challenges for children and adolescents with autism and their families during the Covid-19 pandemic. J Glob Aware 2021;2:1-22.

7 American Psychiatric Publishing. Diagnostic and statistical manual of mental disorders: DSM-5TM. 5th edn. Arlington, VA, US: American Psychiatric Publishing, Inc, 2013.

8 Lord C, Elsabbagh M, Baird G. Autism spectrum disorder. The Lancet 2018:392:508-20.

9 Lai M-C, Kassee C, Besney R, et al. Prevalence of co-occurring mental health diagnoses in the autism population: a systematic review and meta-analysis. Lancet Psychiatry 2019;6:819-29.

10 Mannion A, Leader G. Comorbidity in autism spectrum disorder: a literature review. Res Autism Spectr Disord 2013;7:1595-616.

11 Dakin S, Frith U. Vagaries of visual perception in autism. Neuron 2005;48:497-507.

12 Simmons DR, Robertson AE, McKay LS, et al. Vision in autism spectrum disorders. Vision Res 2009;49:2705-39.

13 Aishworiya R, Kang YQ. Including children with developmental disabilities in the equation during this COVID-19 pandemic. J Autism Dev Disord 2021;51:2155-8. doi:10.1007/s10803-020-04670-6

14 Eshraghi AA, Li C, Alessandri M, et al. COVID-19: overcoming the challenges faced by individuals with autism and their families. Lancet Psychiatry 2020;7:481-3.

15 Pfefferbaum B, North CS. Mental health and the Covid-19 pandemic. N Engl J Med 2020;383:510-2.

16 Usher K, Bhullar N, Jackson D. Life in the pandemic: social isolation and mental health. J Clin Nurs 2020;29:2756-7.

17 Colizzi M, Sironi E, Antonini F, et al. Psychosocial and behavioral impact of COVID-19 in autism spectrum disorder: an online parent survey. Brain Sci 2020;10:341. doi:10.3390/brainsci10060341
18 Renzo MD, Castelbianco FBD, Vanadia E. Parent-Reported behavioural changes in children with autism spectrum disorder during the COVID-19 Lockdown in Italy. Contin Educ 2020;1:117-25.

19 White LC, Law JK, Daniels AM, et al. Brief report: impact of COVID-19 on individuals with ASD and their caregivers: a perspective from the spark cohort. $J$ Autism Dev Disord 2021;51:3766-73. doi:10.1007/s10803-020-04816-6

20 Shum A, Skripkauskaite S, Pearcey S. Report 10: Children and adolescents' mental health: One year in the pandemic 2021;25.

21 Mutluer T, Doenyas C, Aslan Genc H. Behavioral implications of the Covid-19 process for autism spectrum disorder, and individuals' comprehension of and reactions to the pandemic conditions. Front Psychiatry 2020;11:561882.

22 Lee J. Mental health effects of school closures during COVID-19. Lancet Child Adolesc Health 2020;4:421.

23 Ameis $\mathrm{SH}$, Lai M-C, Mulsant $\mathrm{BH}$, et al. Coping, fostering resilience, and driving care innovation for autistic people and their families during the COVID-19 pandemic and beyond. Mol Autism 2020;11:61.

24 Patel JA, Badiani AA, Nielsen FBH, et al. COVID-19 and autism: uncertainty, distress and feeling forgotten. Public Health Pract 2020;1:100034.

25 Drogomyretska K, Fox R, Colbert D. Brief report: stress and perceived social support in parents of children with ASD. J Autism Dev Disord 2020;50:4176-82.

26 Fong V, Gardiner E, larocci G. Satisfaction with informal supports predicts resilience in families of children with autism spectrum disorder. Autism 2021;25:452-63.

27 Asbury K, Fox L, Deniz E, et al. How is COVID-19 affecting the mental health of children with special educational needs and disabilities and their families? J Autism Dev Disord 2021;51:1772-80. doi:10.1007/s10803-020-04577-2

28 Ersoy K, Altin B, Sarikaya BB. The comparison of impact of health anxiety on dispositional hope and psychological well-being of mothers who have children diagnosed with autism and mothers who have normal children, in Covid-19 pandemic. Sos Bilim Araşt Derg 2020;9:117-26.

29 Alhuzimi T. Stress and emotional wellbeing of parents due to change in routine for children with autism spectrum disorder (ASD) at home during COVID-19 pandemic in Saudi Arabia. Res Dev Disabil 2021;108:103822.

30 Canning N, Robinson B. Blurring boundaries: the invasion of home as a safe space for families and children with send during COVID-19 lockdown in England. Eur J Spec Needs Educ 2021;36:65-79.

31 Hoogsteen L, Woodgate RL. Centering autism within the family: a qualitative approach to autism and the family. $J$ Pediatr Nurs 2013;28:135-40.

32 Wright B, Spikins P, Pearson $\mathrm{H}$. Should autism spectrum conditions be characterised in a more positive way in our modern world? Medicina 2020;56:233

33 Mumbardó-Adam C, Barnet-López S, Balboni G. How have youth with autism spectrum disorder managed quarantine derived from COVID-19 pandemic? an approach to families perspectives. Res Dev Disabil 2021;110:103860.

34 Botha M, Frost DM. Extending the minority stress model to understand mental health problems experienced by the autistic population. Soc Ment Health 2020;10:20-34.

35 Waite P, Pearcey S, Shum A. How did the mental health of children and adolescents change during early lockdown during the COVID-19 pandemic in the UK? 2020.

36 van Schalkwyk GI, Marin CE, Ortiz M, et al. Social media use, Friendship quality, and the moderating role of anxiety in adolescents with autism spectrum disorder. J Autism Dev Disord 2017;47:2805-13.

37 Degli Espinosa F, Metko A, Raimondi M, et al. A model of support for families of children with autism living in the COVID-19 Lockdown: lessons from Italy. Behav Anal Pract 2020:1-9.

38 den Houting J. Stepping out of isolation: autistic people and COVID-19. Autism Adulthood 2020;2:103-5.

39 Hedley D, Uljarević M, Foley K-R, et al. Risk and protective factors underlying depression and suicidal ideation in autism spectrum disorder. Depress Anxiety 2018;35:648-57.

40 Kerns CM, Newschaffer CJ, Berkowitz SJ. Traumatic childhood events and autism spectrum disorder. J Autism Dev Disord 2015;45:3475-86.

41 Carr A. What Works with Children and Adolescents?: A Critical Review of Psychological Interventions with Children, Adolescents and their Families. Routledge, 2013.

42 Braun V, Clarke V. To saturate or not to saturate? Questioning data saturation as a useful concept for thematic analysis and sample-size rationales. Qual Res Sport Exerc Health 2019;0:1-16. 
43 Willig C. Qualitative interpretation and analysis in psychology. UK: McGraw-Hill Education, 2012

44 Walton KM, Tiede G. Brief report: Does "healthy" family functioning look different for families who have a child with autism? Res Autism Spectr Disord 2020;72:101527.

45 Midouhas E, Yogaratnam A, Flouri E, et al. Psychopathology trajectories of children with autism spectrum disorder: the role of family poverty and parenting. J Am Acad Child Adolesc Psychiatry 2013;52:1057-65.

46 Achenbach TM, Rescorla L. Achenbach System of Empirically Based Assessment. In: Volkmar FR, ed. Encyclopedia of autism spectrum disorders. New York, NY: Springer, 2013: 31-9.

47 Achenbach TM. Manual for the Child Behavior Checklist/4-18 and 1991 profile. Vermont, US: University of Vermont, Department of Psychiatry, 1999

48 Verhulst FC, Ende vanderJ, Koot HM. Handleiding voor de CBCL/4-18. [Dutch manual for the CBCL/4-18. Rotterdam, The Netherlands: Academic Medical Center Rotterdam/Erasmus University, Sophia Children's Hospital, Department of Child and Adolescent Psychiatry, 1996. https://www.ntvg.nl/artikelen/ handleiding-voor-de-cbcl4-18

49 Achenbach TM, McConaughy SH, Ivanova MY. Manual for the ASEBA brief problem MonitorTM (BPM) 2011;13

50 Piper BJ, Gray HM, Raber J, et al. Reliability and validity of brief problem monitor, an abbreviated form of the child behavior checklist. Psychiatry Clin Neurosci 2014;68:759-67.

51 Achenbach TM. Manual for the Youth Self-Report and 1991 profile. Department of Psychiatry, University of Vermont Burlington, 1991.

52 Roeyers H, Thijs M, Druart C. Social responsiveness scale (SRS-2. Amsterdam: Hogrefe Uitgevers B.V, 2015. https://www. cotandocumentatie.nl/beoordelingen/b/14691/srs-screeningslijstvoor-autismespectrumstoornissen/

53 Noens I, De la Marche W, Scholte E. SRS-A - SRS-A Screeningslijst voor autismespectrumstoornissen bij volwassenen. 3rd edn. Amsterdam: Hogrefe Uitgevers B.V, 2016. https://www.hogrefe.com/ $\mathrm{nl} /$ shop/srs-a-screeningslijst-voor-autismespectrum-stoornissen-bijvolwassenen.html

54 Duvekot J, van der Ende J, Verhulst FC, et al. The screening accuracy of the parent and Teacher-Reported social responsiveness scale (SRS): comparison with the 3Di and ADOS. J Autism Dev Disord 2015;45:1658-72.
55 Bastiaansen D, Koot HM, Bongers IL, et al. Measuring quality of life in children referred for psychiatric problems: psychometric properties of the PedsQL 4.0 generic core scales. Qual Life Res 2004:13:489-95

56 Vermulst A, Kroes G, Meyer RD. Handleiding OBVL, 2015.

57 Roskam I, Raes M-E, Mikolajczak M. Exhausted parents: development and preliminary validation of the parental burnout inventory. Front Psychol 2017;8:163.

58 Veerman JW, Kroes G, De Meyer RE. Opvoedingsbelasting in kaart gebracht. Een kennismaking Met de Opvoedingsbelastingvragenlijst (OBVL). JGZ Tijdschr Voor Jeugdgezondheidsz 2014;46:51-5.

59 De Beurs E. Brief symptom inventory: handleiding addendum [Dutch manual addendum]. Leiden, The Netherlands: PITS B.V., 2004.

60 Derogatis LR, Spencer PM. Brief symptom inventory: BSI. Pearson Upper Saddle River, NJ, 1993.

61 Merikangas K, Milham M, Stringari A. The coronavirus health impact survey (crisis). coronavirus health impact Surv. crisis, 2020. Available: http://www.crisissurvey.org/ [Accessed 8 Jan 2021].

62 Johnson RB, Onwuegbuzie AJ. Mixed methods research: a research paradigm whose time has come. Educ Res 2004;33:14-26.

63 Levitt HM, Motulsky SL, Wertz FJ. Recommendations for designing and reviewing qualitative research in psychology: promoting methodological integrity. Qual Psychol 2017;4:2-22.

64 Fetters MD, Curry LA, Creswell JW. Achieving integration in mixed methods designs-principles and practices. Health Serv Res 2013;48:2134-56.

65 Ivankova NV, Creswell JW, Stick SL. Using mixed-methods sequential explanatory design: from theory to practice. Field Methods 2006;18:3-20.

66 Hesse-Biber S. Qualitative approaches to mixed methods practice. Qual Inq 2010;16:455-68.

67 Henderson JA, Barry TD, Bader SH. The relation among sleep, routines, and externalizing behavior in children with an autism spectrum disorder. Res Autism Spectr Disord 2011;5:758-67.

68 Caregiving LE. and Autism: How Does Children's Propensity for Routinization Influence Participation in Family Activities? OTJR Occup Particip Health 2006;26:69-79.

69 Williams SN, Armitage CJ, Tampe T. Public perceptions of nonadherence to COVID-19 measures by self and others in the United Kingdom. medRxiv 2020. 